\title{
Cannabinoids as Cocrystals
}

\author{
Crist N. Filer \\ PerkinElmer Health Sciences Inc., Boston, MA, USA
}

\section{Dear Editor,}

The fascinating portfolio of Cannabis cannabinoids (phytocannabinoids) [1] continues to grow with new members continually added [2]. Interest in these intriguing natural products has accelerated in recent years, fueled by their potential as medicinal agents [3]. However, along with the promising pharmaceutical opportunity for cannabinoids come some challenging chemistry issues. The first concern is a common property shared by most cannabinoids, namely, their physical state as lipophilic, low melting point semisolids. This physical nature has profound implications. Since crystalline substances are usually more stable than amorphous solids, many cannabinoids have stability limitations. Acidic cannabinoids (functionalized with an aromatic carboxyl $\left[\mathrm{CO}_{2} \mathrm{H}\right]$ group) are especially prone to decarboxylation, but even neutral cannabinoids (lacking a carboxyl group) can be unstable to heat or light. With an estimated $70 \%$ of pharmaceuticals given as tablets [4], the low melting point-semisolid state of most cannabinoids has certainly complicated this convenient administration route for them. Another consequence of the cannabinoid lipophilic nature is their lack of water solubility. In fact, limited water solubility with accompanying delay of drug absorption and bioavailability has been a major problem for many candidate pharmaceuticals like the cannabinoids [5]. Finally, the large number (but smaller individual amounts) of "minor can-
(C) 2022 The Author(s)

Published by S. Karger AG, Basel

This is an Open Access article licensed under the Creative Commons Attribution-NonCommercial-4.0 International License (CC BY-NC) (http://www.karger.com/Services/OpenAccessLicense), applicable to the online version of the article only. Usage and distribution for commercial purposes requires written permission. nabinoids" as a complex mixture in the Cannabis trichomes has confounded their purification and hindered their pharmaceutical development. The purpose of this note is to highlight a recent and exciting alternative approach to these various technical challenges.

Ongoing efforts by cannabinoid chemists to address these daunting obstacles have usually focused on each of them individually. However, the recent return to the 19th century chemistry of "cocrystallization" may well be able to solve some of them simultaneously. This transformative technique is significantly different from traditional crystallization. Cocrystallization involves the intermolecular noncovalent bonding of a molecule of interest (like a cannabinoid) with a companion neutral partner molecule (often termed a "coformer"), crystallizing as a stoichiometric pair in a well-defined and repeating 3-dimensional cocrystal lattice. The discovery of cocrystals is widely attributed to noted German chemist Friedrich Wohler [6] in 1844 and his preparation of quinhydrone, a cocrystal redox couple of quinone and hydroquinone. Wohler was likely unaware of his discovery's significance and the full characterization of quinhydrone as a cocrystal (by X-ray crystal analysis) took more than a century to accomplish.

Cocrystal technology with its many synthetic methods has now been eagerly embraced by the pharmaceutical sector to improve drug stability and bioavailability [7]. Interestingly, early indications that cannabinoids might 
<smiles>O=c1cc(-c2ccc(O)c(O)c2)oc2cc(O)cc(O)c12</smiles>

a<smiles>NC(=O)c1ccncc1</smiles>

c<smiles>O=c1c(O)c(-c2ccc(O)c(O)c2)oc2cc(O)cc(O)c12</smiles>

b

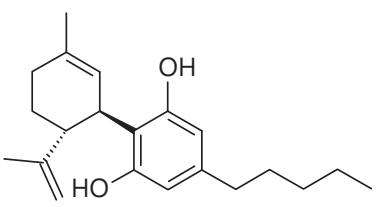

d
Fig. 1. Structures of luteolin (a), quercetin (b), isonicotinamide (c), and cannabidiol $(\mathbf{d})$.

also form cocrystals emerged during the last decade based on discoveries involving related natural products. As shown in Figure 1, the flavonoids luteolin (a) and quercetin (b), both Cannabis constituents, were found to produce cocrystals with the molecular partner isonicotinamide (c) $[8,9]$. Motivation for these studies was the goal of improving the water solubility and the resulting bioavailability of these useful substances. It was inevitable then that cocrystal chemistry would eventually impact cannabinoids themselves. Consequently, cocrystals of cannabinoids like cannabidiol (d) have been recently described and we cite just one of these by an example [10]. Another potential application of this intriguing technology would be identification of unique cocrystal pairs of minor cannabinoids to facilitate their purification from a complex host of other Cannabis constituents.

The trichome laden Cannabis flower produces a cornucopia of diverse cannabinoids with pharmaceutical potential but also accompanying physical chemistry challenges. Cocrystal chemistry with the ability to modify the characteristics of its several components is now enjoying a renaissance of interest since its discovery over 175 years ago. For these reasons, cocrystal technology is likely to significantly enhance the physical properties of cannabinoids and accelerate their pharmaceutical development.

\section{Conflict of Interest Statement}

The author declares that he has no conflict of interest.

\section{Funding Sources}

The author did not receive any funding.

\section{Author Contributions}

The author prepared the manuscript and approved the final version.

\section{References}

1 Hanus LO, Meyer SM, Munoz E, TaglialatelaScafati O, Appendino G. Phytocannabinoids: a unified critical inventory. Nat Prod Rep. 2016;33(12):1357-92.

2 Chianese G, Lopatriello A, Schiano-Moriello A, Caprioglio D, Mattoteia D, Benetti E, et al. Cannabitwinol, a dimeric phytocannabinoid from hemp, Cannabis sativa L., is a selective thermo-TRP modulator. J Nat Prod. 2020; 83(9):2727-36.

3 Ben Amar M. Cannabinoids in medicine: a review of their therapeutic potential. J Ethnopharmacol. 2006;105:1-25.
4 Pitt KG. Chapter 4. Tablet formulation. RSC Drug Disc Ser. 2018;64:78-104.

5 Coltescu A-R, Butnariu M, Sarac I. The importance of solubility for new drug molecules. Biomed Pharmacol J. 2020;13(2):577-83.

6 Wohler F. Untersuchungen uber das chinon. Ann Chem Pharm. 1844;51:145-63.

7 Childs SL, Zaworotko MJ. The reemergence of cocrystals. The crystal clear writing is on the wall: introduction to virtual special issue on pharmaceutical cocrystals. Cryst Growth Des. 2009;9(10):4208-11.
8 Sowa M, Slepokura K, Matczak-Jon E. Cocrystals of fisetin, luteolin and genistein with pyridinecarboxamide coformers: crystal structures, analysis of intermolecular interactions, spectral and thermal characterization. Cryst Eng Comm. 2013;15(38):7696-708.

9 Smith AJ, Kavuru P, Wojtas L, Zaworotko MJ, Shytle RD. Cocrystals of quercetin with improved solubility and oral bioavailability. Mol Pharm. 2011;8(5):1867-76.

10 Emanuele RM, Shattock-Gordon T, Williford T, Andres M, Andres P. Solid forms of cannabidiol and uses thereof. United States Patent 10604467 B2. 2020. 